\title{
Multiple notches on the spleen, an important differential diagnosis for rupture spleen: An anatomical appraoch
}

\author{
Shivakumar A.H ${ }^{1}$, Sumana $\mathbf{R}^{2 *}$ \\ ${ }^{1}$ Professor, ${ }^{2}$ Professor and Head, Dept. of Anatomy, ${ }^{1} \mathrm{JJM}$ Medical College, Davangere, Karnataka, ${ }^{2}$ Velammal Medical College Madurai \\ Tamil Nadu, India
}

*Corresponding Author: Sumana R

Email: sumsdr@rediffmail.com

\begin{abstract}
The spleen acts as a filter for blood removing the unwanted materials from blood. It is also a production house for the RBCs in pre-natal life, and post-natal period it produces Lymphocytes hence called a lymphoid organ \& destroys aged RBCs. The spleen shows notches along its borders. These notches represent the fetal lobulated spleen. The present research study focuses on the notches denoting the incidence of lobulated spleens. In the present study, the spleen from fifty embalmed cadavers was collected during routine dissection in, Department of Anatomy $\&$ the findings of the present research study will be of fundamental importance to the physicians, surgeons, radiologists, and anatomists.
\end{abstract}

Keywords: Spleen, Splenic notches, Lobulated spleen, Rupture spleen.

\section{Introduction}

The spleen having two surfaces; diaphragmatic surface (convex and smooth) and visceral surface (irregular), two poles, the anterior pole directed laterally and the posterior pole facing the vertebral column, two borders, superior and inferior (Chaware et al., 2012). The visceral surface is marked by gastric, renal, colic, and pancreatic impressions created by adjacent organs \& is related to left 9th, 10th, and 11th ribs (Patil et al., 2014).

The spleen being one of the largest organs with high vascularity, the shape of which varies from a curved wedge, triangular, to a domed tetrahedron (Gandhi and Chavan, 2013), is suspended in the upper left quadrant of the abdominal cavity between the fundus of the stomach and the diaphragm, with considerable variations in the size and weight with age, due delibrations to its main function of filtration. In adults; it is usually $12 \mathrm{~cm}$ long, $7 \mathrm{~cm}$ broad and $3-4 \mathrm{~cm}$ wide. Its average adult weight is $150 \mathrm{~g}$, the normal range is wide, between 80 and $300 \mathrm{~g}$ (Nayak et al., 2014).

According to previous studies the superior border, near the anterior pole, there may be one or two notches, persisting from the lobulated form of the spleen in early fetal life (Yildiz et al., 2013). There are records of accessory spleen being detected as a fully functional splenic tissue totally detached from spleen may exist near the spleen. The most common places where the Accessory spleens are found are at the hilum of the spleen, in the gastrosplenic ligament and in the lienorenal ligament in the greater omentum (Kumari et al., 2014).
During fetal life the spleen develops from the mesoderm, numerous lobules are formed, which fuses with each other in the form of the lobulations which can be seen as notches in adult spleen more commonly at the superior border rarely at the inferior borders. The number of notches varies from 0 to 6 , but commonly, only one or two notches are seen.

\section{Materials and Methods}

First the spleen was located $\&$ dissected from the abdominal cavity, detached from its various attachments, and the splenic vessels were cut near the hilum after ligation. To maintain the anatomy in situ, en masse removal of abdominal viscera was carried out. All the dissected spleen were then washed with water to clean the debris and the fatty tissue. They were weighed on an electronic weighing machine and their lengths, breadths, and widths were measured wernier calipers. The shape, poles, borders, surfaces, and the impressions on the spleen were observed. Accessory splenic tissues, if they were present, were noted we considered the greatest distance between the two poles of the spleen as its length, the greatest distance between two points at the same level on the superior and inferior borders as its breadth and the greatest width as the width of the spleen. The data which was thus obtained was analyzed and compared with that of previous studies.

\section{Observations}

The detailed observation noted are tabulated below:

Table 1

\begin{tabular}{|c|c|c|c|c|}
\hline Specimen no & $\begin{array}{c}\text { No of notches in the } \\
\text { superior border }\end{array}$ & $\begin{array}{c}\text { No of notches in the } \\
\text { inferior border }\end{array}$ & Shape & $\begin{array}{c}\text { Length } \\
\text { Breath Thickness in cm }\end{array}$ \\
\hline 1 & 1 & - & Trinagular & $11,8,3.5$ \\
\hline 2 & 1 & - & Wedge & $12,7,4$ \\
\hline 4 & 1 & - & Dome & $11.5,6,4$ \\
\hline
\end{tabular}




\begin{tabular}{|c|c|c|c|c|}
\hline 5 & 1 & - & Dome & $11.5,5,3.5$ \\
\hline 6 & 1 & - & Wedge & $11,8,3.5$ \\
\hline 7 & 1 & - & Wedge & $12,8,4$ \\
\hline 8 & 1 & - & Dome & $11,8,4$ \\
\hline 9 & 1 & 1 & Trinagular & $11,8,3.5$ \\
\hline 10 & 3 & 3 & wedge & $13,8,3.5$ \\
\hline 11 & 1 & - & Dome & $10,7.5,4$ \\
\hline 12 & 1 & - & Wedge & $11,8,3.5$ \\
\hline 13 & 1 & - & Wedge & $10,8,4$ \\
\hline 14 & 1 & - & Trinagular & $11,8,4$ \\
\hline 15 & 1 & - & Dome & $11,8,3.5$ \\
\hline 16 & 1 & 1 & Wedge & $12,8,3.5$ \\
\hline 17 & 1 & 1 & Dome & $12,9,4.5$ \\
\hline 18 & 2 & - & Wedge & $11,8,3.5$ \\
\hline 19 & 2 & - & Trinagular & $12,8.5,3.5$ \\
\hline 20 & 1 & - & Dome & $11,9,4$ \\
\hline 21 & 1 & - & Dome & $12,9,4$ \\
\hline 22 & 1 & - & Trinagular & $11,8,3.5$ \\
\hline 23 & 1 & - & Wedge & $13.5,9,4$ \\
\hline 24 & 4 & 3 & dome & $14,8,4$ \\
\hline 25 & 1 & - & Wedge & $12,9,3.5$ \\
\hline 26 & 1 & - & Trinagular & $10,8,3.5$ \\
\hline 27 & 1 & - & Wedge & $12,7,4$ \\
\hline 28 & 1 & - & Dome & $11.5,6,4$ \\
\hline 29 & 1 & - & Trinagular & $11,8,3.5$ \\
\hline 30 & 1 & - & Dome & $10.5,5,3.5$ \\
\hline 31 & 2 & 1 & Wedge & $11,8,3.5$ \\
\hline 32 & 1 & - & Wedge & $12,8,4$ \\
\hline 33 & 2 & - & Dome & $11,8,4$ \\
\hline 34 & 1 & - & Trinagular & $10,8,3.5$ \\
\hline 35 & 1 & - & wedge & $13,8,3.5$ \\
\hline 36 & 1 & - & Dome & $10,7.5,4$ \\
\hline 37 & 1 & - & Wedge & $12,8,3.5$ \\
\hline 38 & 1 & - & Wedge & $10,8,4$ \\
\hline 39 & 1 & - & Trinagular & $11,8,4$ \\
\hline 40 & 2 & - & Dome & $10,8,3.5$ \\
\hline 41 & 1 & - & Wedge & $12,8,3.5$ \\
\hline 42 & 1 & 1 & Dome & $12,9,4.5$ \\
\hline 43 & 1 & - & Wedge & $10,8,3.5$ \\
\hline 44 & 1 & - & Trinagular & $12,8.5,3.5$ \\
\hline 45 & 1 & - & Dome & $11,9,4$ \\
\hline 46 & 1 & - & Dome & $12,9,4$ \\
\hline 47 & 1 & - & Trinagular & $10,8,3.5$ \\
\hline 48 & 1 & - & Wedge & $13.5,9,4$ \\
\hline 49 & 1 & - & dome & $14,8,4$ \\
\hline 50 & 1 & - & Wedge & $12,9,3.5$ \\
\hline
\end{tabular}

\section{Results and Discussion}

During the study of 50 spleens two lobulated spleens with multiple hila and fissures were noted which are described in detail as follows. Other routene findings like the diaphragmatic surface of the spleen showed a uniform morphology while its visceral surface showed cadaveric impressions of stomach, renal, colic, and pancreas were also noted. The splenic notches whether present on the superior or inferior or both borders was also noted.
Specimen I (no.10 in the table) had the largest division of the hilum which was situated at highest above the intermediate border near the anterior end of the spleen. The other two hila were situated closer to the intermediate border of the spleen on the visceral surface. Upper border of the spleen presented three fissures or the notches. The lower border of the spleen also featured three fissures seen on both visceral and diaphragmatic surfaces of the spleen. 
Specimen II (No.24 in the table) had 4 notches in the superior border and 3 notches on the inferior border and was the biggest of all the spleens taken for the study.

The fissure pattern of both specimen was seen as a notch in diaphragmatic surface. Two fissures from superior border were deep and directed downward. The visceral peritoneum of the spleens extended completely till the bottom of all the fissures in both specimens. Because of the presence of these fissures, the spleen had a characteristic multilobulated appearance with distinct lobes/lobules as shown in the picture.

In the present study, the splenic notches were found on the superior as well as on the inferior borders. The number of notches seen was upto six, but commonly, there were only one or two notches. These findings of the present study were in accordance with those of the earlier studies.

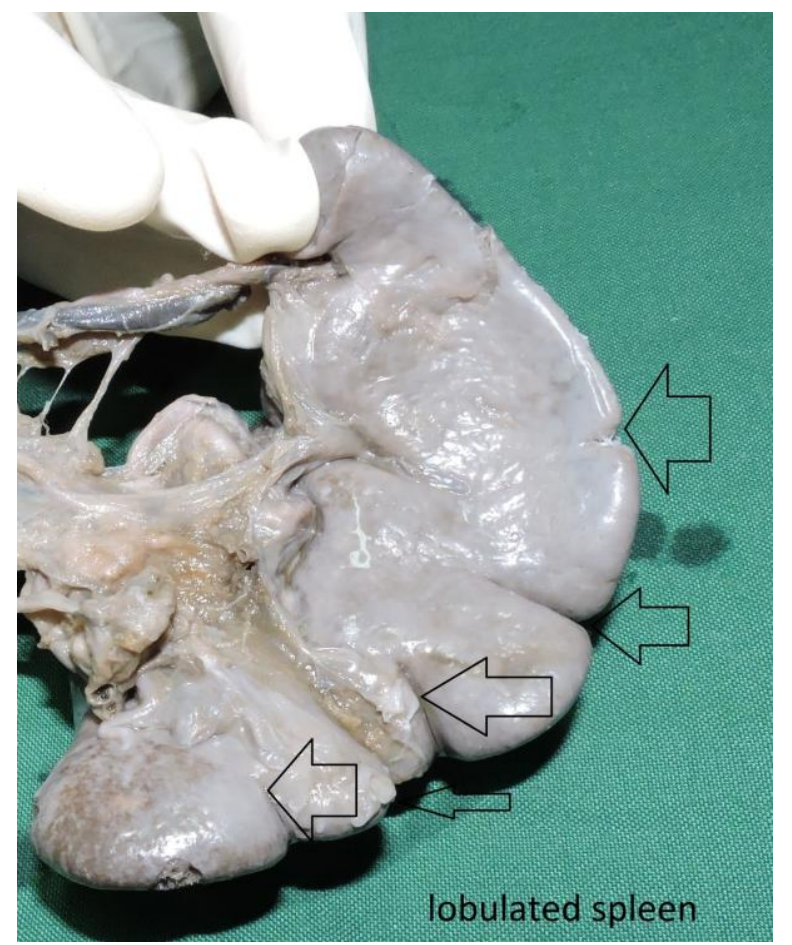

Fig. 1

\section{Discussion}

The spleen is a morphologically variable organ with respect to its size, shape, fissures, and position. Its variations might result in diagnostic pitfalls (Setty and Katikireddi, 2013). The studies have shown that the spleen may retain its fetal lobulated patterns.

In splenomegaly the anterior end and diaphragmatic surface may become palpable below left costal margin. The notches if present are often exaggerated and may be easily palpable. Splenomegaly is common in the case of malaria, typhoid, and leukemia. When the spleen is enlarged, it enlarges toward the umbilicus and right iliac fossa. The option of Surgeons doing segmental splenectomy is in practice. However, the importance of the spleen in protection from infection by acting as a filter for blood is offen neglected, a series of recent animal experiments and patients' follow-up studies revealed its actual importance in protection from blood born sepsis, where its role as a blood filter was found to be significant (Alshukry, 2008).

Hence, despite the overwhelming indications for splenectomy in traumatic rupture, hypersplenism, neoplasia, and splenic cyst, the tendency of the surgeons is to conserve as much splenic tissue as possible. The appearance of fissures on the spleen may mislead the surgeons as a traumatic injury. Hence we strongly feel that the through knowledge of the anatomy and anatomical variation in form of fissures will help surgeon to differentiate between a variation in form of fissure even in lower border and a tear due to injury.

\section{Conclusion}

Splenic notches are very common on the superior border than on the inferior border. It is essential for the surgeons and radiologists to be aware of anatomical variations that help in clinical diagnosis and treatment of disease. The appearance of fissures on the spleen may mislead the surgeons as a traumatic injury. The knowledge of this variation is important radiologically, and surgically. The notches in form of fissures are commoner than rare and can even be on the inferior border.

\section{Conflict of Interest: None.}

\section{References}

1. Alshukry, S.M. Splenic torsion. Oman Med J 2008;23(4):2878.

2. Chaware, P.N., Belsare, S.M., Kulkarni, Y.R., Pandit, S.V. \& Ughade, J.M. The morphological variations of the human spleen. J Clin Diagn Res 2012;6(2):159-62.

3. Gandhi, K.R., Chavan, S.K. \& Oommen, S.A. Spleen with multiple notches: A rare anatomical variant with its clinical significance. Int J Students Res 2013;3(1):24-5.

4. Kumari K.D., Sushma M., Lakshmi Sailaja, L. \& Asha Latha, D. Notches of the Spleen. J Evid Based Med Healthc 2014;1:1090-3.

5. Nayak, S.B., Shetty, P., Deepthinath, R., Sirasanagandla, S.R. \& Setty, S.D. A lobulated spleen with multiple fi ssures and Hila. J Clin Diagn Res 2014;8(9).

6. Patil G.V., Shishirkumar V., Apoorva D., Thejeswari D.J.S., Sheshgiri C. \& Sushanth, N.K. Study of splenic notches in a human cadaver. Int J Recent Adv Multidiscip Res 2014;1:1-3.

7. Setty, S.N. \& Katikireddi, R. A cadaveric study of human splenic notches and fissures. Int J Health Sci Res 2013;3(9):404.

8. Yildiz, A.E., Ariyurek, M.O. \& Karcaaltincaba, M. Splenic anomalies of shape, size, and location: Pictorial essay. Sci World J 2013;2013:1-9.

How to cite this article: Shivakumar AH, Sumana R.
Multiple notches on the spleen, an important differential
diagnosis for rupture spleen: An anatomical approach.
Indian J Anat Surg Head Neck Brain 2019;5(2):48-50.

